\title{
ДОСЛІДЖЕННЯ ПАРАМЕТРІВ ПРОЦЕСУ МИТТЯ ДЕТАЛЕЙ В УЛЬТРАЗВУКОВІЙ ВАННІ
}

\author{
Олександр Левчук, к. т. н., Роман Кузьмінський, д. т. н. \\ Львівський національний аграрний університет, \\ вул. Володимира Великого, 1, м. Дубляни, Львівський р-н, Львівська обл., Украӥна, \\ e-mail:levchuklnau@gmail.com
}

https://doi.org/10.31734/agroengineering2021.25.057

\begin{abstract}
Левчук О., Кузьмінський Р. Дослідження параметрів процесу миття деталей в ультразвуковій ванні
Огляд і аналіз теорій щодо використання ультразвуку для очищення деталей дає підстави вважати доцільним пошук нових шляхів для оптимізації цього процесу, а також виведення нових математичних моделей для більш точного опису з урахуванням впливу різних факторів.

Метою дослідження було визначення впливу трьох основних факторів на процес миття забруднених деталей 3 використанням ультразвуку. Як стенд було вибрано ультразвукову ванну Ultrasonic Cleaner JP-031S об'ємом 6,5 л 3 частотою ультразвукового випромінювача $40 \mathrm{KHz}$ і потужністю ультразвукового випромінювача $180 \mathrm{~W}$, а як об'єкти миття - 24 штучно забруднені фрагменти труби квадратного профілю 3 відхиленням у масі не більше як $1,15 \%$ між собою.

Було здійснено повний факторний експеримент за умови впливу таких факторів: тривалість миття, температура мийного розчину, концентрація водного розчину мийних компонентів. Критерієм оптимізації обрано відсоток змитого забруднення.

Створено матрицю реалізації плану ПФЕ $2^{3}$. Відтворюваність результатів експерименту була підтверджена за допомогою критерію Кохрена, що дало змогу вивести рівняння регресії в загальному вигляді і розрахувати його коефіцієнти. Значущість коефіцієнтів була визначена за допомогою критерію Стьюдента, а дисперсія адекватності виправленої моделі була підтверджена за допомогою критерію Фішера. Таким чином було встановлено, що два фактори: $x 1, x 2$ (відповідно час миття і температура мийного розчину) - 395 \%-вою вірогідністю є значущими.

Після переходу рівняння регресії до розкодованого вигляду було отримано математичну модель, яка дозволяє розрахунковим способом знайти процент змитого забруднення, враховуючи розглянуті фактори, і може бути використана для майбутніх розрахунків оптимізації процесу миття забруднених деталей.

На основі рівняння регресії були побудовані поверхні відгуку, в яких залежності є надзвичайно близькі до лінійних, за збільшення часу миття, температури мийного розчину і концентрації водного розчину мийних компонентів збільшується відсоток змитого забруднення.
\end{abstract}

Ключові слова: ультразвукове очищення, критерії оптимізації, відсоток змитого забруднення, поверхні відгуку.

Levchuk O., Kuzminskyi R. Research of parameters of the process of washing of details in an ultrasonic bath

The review and analysis of the theories on the use of ultrasound for cleaning parts gives reason to consider it expedient to search for new ways to optimize this process, as well as to develop new mathematical models for a more accurate description, taking into account the influence of various factors.

The purpose of the research was to determine the influence of three main factors on the process of washing contaminated parts using ultrasound. An ultrasonic cleaner Ultrasonic Cleaner JP-031S with a volume of 6.5 liters with a frequency of an ultrasonic emitter of $40 \mathrm{KHz}$ and a power of an ultrasonic emitter of $180 \mathrm{~W}$ and 24 artificially contaminated fragments of a square tube with a mass deviation of no more than $1.15 \%$ among themselves was chosen as a stand.

A full factorial experiment was carried out under the condition of influence of the following factors: duration of washing, temperature of the washing solution, concentration of an aqueous solution of washing components. The optimization criterion was the percentage of washed off contamination.

A matrix was created for implementation of the full factorial design $2^{3}$. The reproducibility of the experimental results was confirmed using the Cochran's $\mathrm{C}$ test, which made it possible to derive the regression equation in general form and calculate its coefficients. The significance of the coefficients was determined using the Student's test, and the variance of the adequacy of the corrected model was confirmed using the F-test. Thus, it was found that two factors $x 1, x 2$ (the duration of washing and temperature of the washing solution respectively) are significant with a $95 \%$ probability.

After transition of the regression equation to the decoded form, a mathematical model was obtained. The model allows calculating the percentage of washed off contamination taking into account the factors considered and can be used for future calculations of optimization of the process of washing contaminated parts.

On the basis of the regression equation, the response surfaces were constructed, in which the dependences were extremely close to linear ones, i.e. as the washing time, the temperature of the washing solution and the concentration of the aqueous solution of washing components increased, the percentage of washed off contamination increased too.

Key words: ultrasonic cleaning, optimization criteria, percentage of washed off contamination, response surfaces. 
Постановка проблеми. Ультразвукове очищення - це процес, який використовує ультразвук для перемішування мийного розчину. Він використовує кавітаційні бульбашки, індуковані високочастотним тиском (звуковими хвилями) i створює високі сили дії на забруднювачі, які прилипають до різних матеріалів. Утворення кавітаційних бульбашок при очищенні деталі є складним процесом, на який впливає багато факторів. Серед них: температура мийного розчину, концентрація мийної рідини, склад мийної рідини, форма і матеріал деталі, потужність ультразвукового випромінювача, склад забруднювача, час очищення деталі тощо. Відповідно варіації i комбінації цих факторів впливають на утворення кавітаційних бульбашок у відмінних між собою кількостях, а також на очищення деталі з різною ефективністю, що дає підстави для проведення низки дослідів 3 метою встановлення найбільш ефективного й економічного режиму миття деталі.

Огляд і аналіз теорій щодо використання ультразвуку для очищення деталей $[2-6 ; 10 ; 12]$ дає підстави вважати доцільним пошук нових шляхів для оптимізації цього процесу, а також виведення нових математичних моделей для більш точного опису 3 урахуванням впливу різних факторів. Зважаючи на результати попередніх досліджень $[7 ; 8 ; 11 ; 13 ; 14]$, можна стверджувати, що на процес миття найбільший вплив мають такі фактори: температура мийного розчину, концентрація мийної речовини і час очищення деталі. Тому для нашого дослідження вибрані саме ці фактори.

Аналіз останніх досліджень і публікацій. На сьогодні проведена велика кількість досліджень миття деталей із використанням ультразвуку. Більшість із них стосується використання ультразвукового очищення деталей у промисловому масштабі. Наприклад, у статті [7] наведено результати дослідження впливу температури i концентрації різних мийних речовин на ефективність миття. У праці [13] розглядається вплив температури мийного розчину і частоти ультразвукового випромінювання на кількість змитого забруднення. Однак у літературі нами не було знайдено експериментальних досліджень щодо використання малогабаритних $(5-10$ л) ультразвукових ванн для миття деталей 3 урахуванням трьох основних факторів.

Постановка завдання. Метою дослідження $\epsilon$ створення й аналіз математичної моделі впливу тривалості миття, температури мийного розчину i концентрації водного розчину мийних компонентів на кількість змитого забруднення в ультразвуковій ванні Ultrasonic Cleaner JP-031S.

Виклад основного матеріалу. Як об'єкти миття використано фрагменти труби квадратного профілю розмірами $50 \times 50$ мм довжиною 50 мм. Аналіз умов роботи сільськогосподарської техніки показує, що основними забрудниками є поєднання залишків грунту з рослинними та іншими органічними матеріалами й суміш нафтопродуктів різноманітного походження (пально-мастильні матеріали, консерваційні композиції). Для створення імітації одноманітного забруднення було використано наступні матеріали і технологію. Спочатку зразок занурювали в суспензію суглинкового грунту, взятого 3 поверхні орного шару поля. Надлишки забруднювальної суміші струшували дворазовим обстукуванням по краю ємності. Потім зразок сушили до вологості навколишнього середовища (приміщення лабораторії з температурою повітря близько $22 \square$ ). Далі зразок поміщали в суміш будівельного бітуму - $20 \%$ і відпрацьованого моторного мастила - $80 \%$. Температура суміші становила $150 \square$. Зразки були розташовані на пористому картоні для охолодження і вбирання надлишку забруднювальної суміші. Після охолодження й витримки на адсорбуючому матеріалі (пористий картон) упродовж однієї доби зразки було зважено на вазі моделі PS 510. R1 із точністю до 0,01 г (рис. 1).

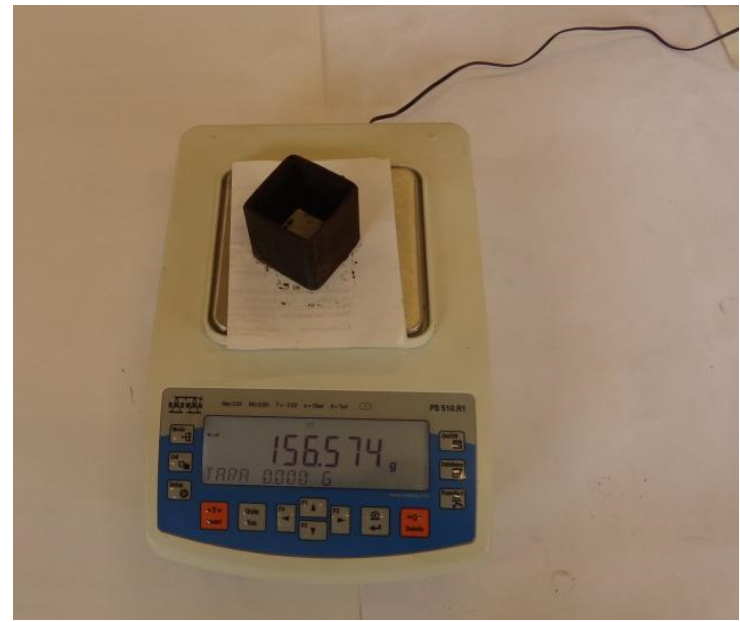

Рис. 1. Процес зважування забрудненої деталі

Fig. 1. The process of weighing contaminated part

Як мийний засіб використано розчин карбонату натрію (кальцинована сода $\mathrm{Na}_{2} \mathrm{CO}_{3}$ ) i суміш поверхнево-активних речовин у пропорції 9:1 (виходячи з умісту сухих компонентів). Як 
суміш поверхнево-активних речовин використано засіб для миття посуду, що містить композицію трьох основних компонентів (поверхнево-активних речовин трьох типів).

Аналіз відсоткового вмісту компонентів мийного засобу показав, що вони становлять 9,5 \%. Виходячи 3 цих умов, створювали мийний розчин. Далі здійснювали процес миття зразків за планом (табл. 1, 2) [1; 9] у три серії в рандомізованому порядку (цифри - порядковий номер зразка):

для першої серії - 7, 6, 2, 5, 4, 1, 8, 3;

для другої - 4, 1, 6, 8, 7, 3, 5, 2;

для третьої-8, 6, 2, 7, 1, 5, 3, 4 (рис. 2).

Далі кожен зразок був знову висушений i зважений (рис. 3). Таким чином було підраховано відсоток змитого забруднення в кожному 3 дослідів (табл. 3).

Кожен дослід був повторений однакову кількість разів, що дозволяє перевірити відтворюваність результатів за допомогою критерію Кохрена. Результати є відтворювані, якщо критерій Кохрена при 5-відсотковому рівні значущості:

$$
G p=\frac{s_{u M a x}^{2}}{\sum_{u=1}^{n} s_{u}^{2}} \leq G m\left(0,05 ; n ; f_{u}\right) .
$$

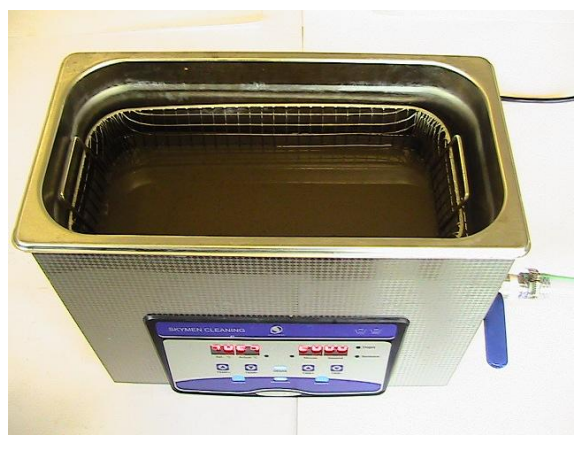

Рис. 2. Процес миття в ультразвуковій ванні

Fig. 2. The process of washing in ultrasonic bath

Табличне значення критерію Кохрена при числі незалежних оцінок дисперсії $n=8$ і числі степенів вільності кожної оцінки $f_{u}=2$ буде 0,516 .

$$
\text { Розрахункове значення } G p=\frac{113,1}{330,8}=0,341 \text {. }
$$

Розрахункове значення критерію Кохрена $є$ меншим від табличного. Із цього робимо висновок, що процес $є$ відтворюваним.

Математична модель для плану 1-го порядку являє собою неповне квадратне рівняння

$$
\begin{aligned}
& y=b_{0}+b_{1} x_{1}+b_{2} x_{2}+b_{3} x_{3}+b_{12} x_{1} x_{2}+ \\
& +b_{13} x_{1} x_{3}+b_{23} x_{2} x_{3}+b_{123} x_{1} x_{2} x_{3}
\end{aligned}
$$

Таблиця 1. Числові значення змінних параметрів ( $t$ - тривалість процесу миття, $T$ - температура розчину, $p$ - концентрація мийних речовин)

Table 1. Figures of variable parameters $(t$ - duration of the washing process, $T$ - solution temperature, $p-$ concentration of detergents)

\begin{tabular}{|c|c|c|c|c|}
\hline \multirow{2}{*}{ № досліду } & Фіктивна змінна* & $t, \mathrm{xB}$ & $T, \square$ & $p$, г/л \\
\hline & $x 0$ & $x 1$ & $x 2$ & $x 3$ \\
\hline 1 & + & + & - & - \\
\hline 2 & + & - & - & - \\
\hline 3 & + & + & + & - \\
\hline 4 & + & - & + & - \\
\hline 5 & + & + & - & + \\
\hline 6 & + & - & - & + \\
\hline 7 & + & + & + & + \\
\hline 8 & + & - & + & + \\
\hline
\end{tabular}

\begin{tabular}{|c|c|c|c|}
\hline Рівень факторів & $t$, хв & $T, \square$ & $p, \Gamma /$ л \\
\hline- & 5 & 40 & 5 \\
\hline 0 & 10 & 60 & 15 \\
\hline+ & 15 & 80 & 25 \\
\hline
\end{tabular}

Таблиця 2. План проведення дослідів із кодованими значеннями факторів

Table 2. Test plan with coded factor values

*Стовпчик 2 виводиться для зручності проведення розрахунків і називається фіктивною змінною $x 0$.

*Column 2 is displayed for the convenience of calculations and is called the dummy variable $x 0$. 


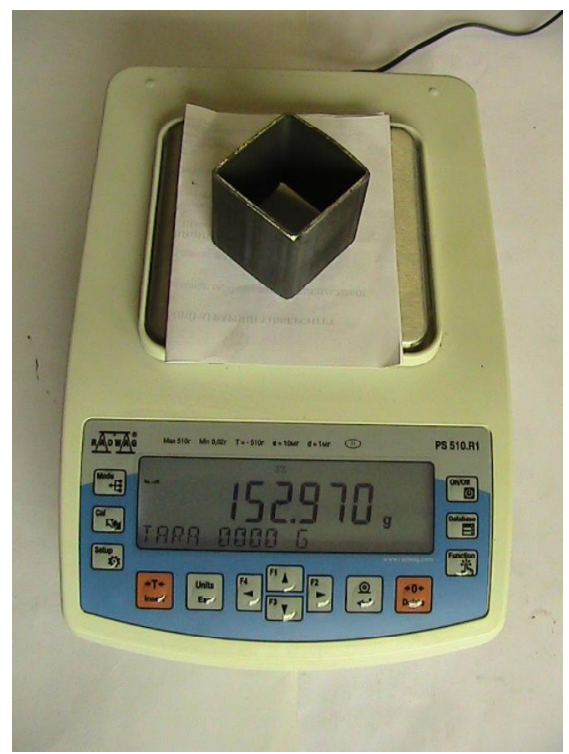

$a$

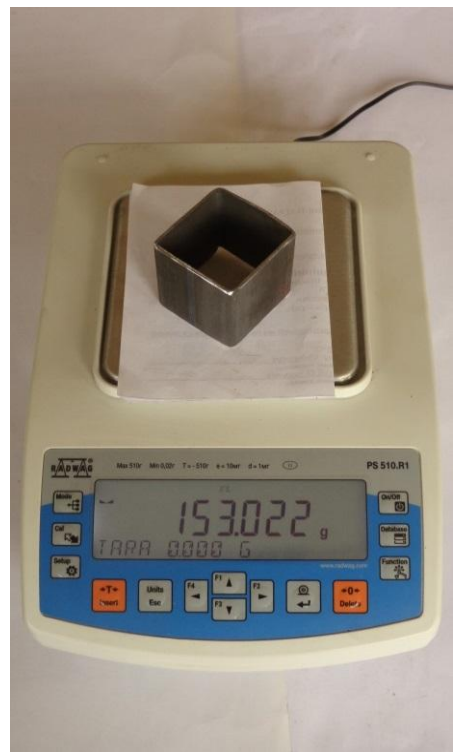

6

Рис. 3. Процес зважування чистих деталей

Fig. 3. The process of weighing clean parts

За допомогою методу найменших квадратів були виведені формули для знаходження коефіцієнтів рівняння регресії:

$$
\begin{aligned}
& b_{0}=\frac{1}{N} \sum_{p=1}^{N} x_{0 j} y_{j}=\frac{1}{N} \sum_{p=1}^{N} y ; b_{i}=\frac{1}{N} \sum_{p=1}^{N} x_{i j} y_{j} ; \\
& b_{i k}=\frac{1}{N} \sum_{p=1}^{N} x_{i j} x_{k j} y_{j} ; \quad b_{i s k}=\frac{1}{N} \sum_{p=1}^{N} x_{i j} x_{s j} x_{k j} y_{j} ;
\end{aligned}
$$

Після обробки експериментальних даних (див. табл. 3 i 4) отримано рівняння регресії в загальному вигляді:

$$
\begin{aligned}
& y=37,5+9,18 x_{1}+14,19 x_{2}+5,21 x_{3}+2,41 x_{1} x_{2}- \\
& -1,86 x_{1} x_{3}+6,49 x_{2} x_{3}+0,46 x_{1} x_{2} x_{3}
\end{aligned}
$$

Було здійснено оцінку значущості коефіцієнтів регресії за допомогою критерію Стьюдента:

$$
\left|b_{a}\right| \geq \Delta b_{a}=t\left(0,05 ; f_{i}\right) \frac{S_{y}}{\sqrt{n}} .
$$

Табличне значення критерію Стьюдента при 5-відсотковому рівні значущості і числі степенів вільності дисперсій відтворюваності буде 2,12.

Отже, значення довірчого інтервалу $\Delta b_{a}$ при середній дисперсії $S_{y}=2,53$

$$
\Delta b_{a}=2,12 \frac{2,53}{\sqrt{8}}=4,82 .
$$

На основі визначеного критерію можна стверджувати, що для даного рівняння регресії значущими $є$ такі коефіцієнти:

$$
b_{0}, b_{1}, b_{2}, b_{3}, b_{23} .
$$

Тоді рівняння регресії набуде вигляду:

$$
y=37,5+9,18 x_{1}+14,19 x_{2}+5,21 x_{3}+6,49 x_{2} x_{3}
$$

Дисперсія адекватності отриманої моделі визначається за допомогою критерію Фішера. Модель $є$ адекватною, якщо критерій Фішера при 5-відсотковому рівні значущості:

$$
F_{p}=\frac{s_{a d}^{2}}{s_{y}^{2}} \leq F_{T}\left(0,05 ; f_{a d} ; f_{u}\right) .
$$

Табличне значення критерію Фішера при числі степенів вільності дисперсії адекватності $f_{a d}=3$ і числі степенів вільності дисперсії відтворюваності $f_{y}=16$ буде 3,23 .

$$
\frac{S_{a d}^{2}}{S_{y}^{2}}=\frac{20,66}{41,35}=0,49 .
$$

Розрахункове значення критерію Фішера $\epsilon$ меншим від табличного, відповідно отримана модель адекватна експерименту i може бути використана для опису процесу.

Це дає змогу перейти від кодованих значень $x 1, x 2, x 3$ до їх натуральних значень:

$$
Y=-2,04+1,83 X_{1}+0,22 X_{2}-1,42 X_{3}+0,03 X_{2} X_{3} \text {. (4) }
$$

На основі рівняння (3) були побудовані поверхні відгуку. Під час побудови поверхонь відгуку змінювались тільки два фактори, а третій дорівнював нулю. 
Таблиця 3. Реалізація плану ПФЕ $2^{3}$

Table 3. Design matrix and resulting washed off pollution value

\begin{tabular}{|c|c|c|c|c|c|c|c|c|}
\hline \multirow{2}{*}{$\begin{array}{c}\text { № } \\
\text { досліду }\end{array}$} & \multicolumn{4}{|c|}{ Матриця плану } & \multicolumn{3}{|c|}{$\begin{array}{c}\text { Відсоток змитого забруднення } \\
\text { в дослідах }\end{array}$} & \multirow{2}{*}{$\begin{array}{c}\text { Cep. } \\
\text { знач. } \\
y \mathrm{j} \\
\end{array}$} \\
\hline & $x 0$ & $x 1$ & $x 2$ & $x 3$ & $y 1$ & $y 2$ & $y 3$ & \\
\hline 1 & + & + & - & - & 28,5 & 31,3 & 41,2 & 33,7 \\
\hline 2 & + & - & - & - & 17,6 & 12,5 & 16,4 & 15,5 \\
\hline 3 & + & + & + & - & 51,1 & 43,5 & 64,5 & 53 \\
\hline 4 & + & - & + & - & 22,5 & 24,7 & 33,5 & 27 \\
\hline 5 & + & + & - & + & 25,5 & 21,6 & 32,6 & 26,5 \\
\hline 6 & + & - & - & + & 20,4 & 14,6 & 17,9 & 17,6 \\
\hline 7 & + & + & + & + & 66,7 & 73,9 & 80,2 & 73,6 \\
\hline 8 & + & - & + & + & 48,4 & 50,1 & 61,2 & 53,2 \\
\hline
\end{tabular}

Таблиця 4. Розширена матриця плану ПФЕ $2^{3}$

Table 4. Extended design matrix of full factorial experiment

\begin{tabular}{|c|c|c|c|c|c|c|c|c|c|}
\hline \multirow{2}{*}{$\begin{array}{c}\text { № } \\
\text { досліду }\end{array}$} & \multicolumn{3}{|c|}{ Матриця плану } & \multirow{2}{*}{$x 0$} & \multirow{2}{*}{$x 1 x 2$} & \multirow{2}{*}{$x 1 x 3$} & \multirow{2}{*}{$x 2 \times 3$} & \multirow{2}{*}{$x 1 \times 2 \times 3$} & \multirow{2}{*}{ yj } \\
\hline & $x 1$ & $x 2$ & $x 3$ & & & & & & \\
\hline 1 & + & - & - & + & - & - & + & + & 33,7 \\
\hline 2 & - & - & - & + & + & + & + & - & 15,5 \\
\hline 3 & + & + & - & + & + & - & - & - & 53 \\
\hline 4 & - & + & - & + & - & + & - & + & 27 \\
\hline 5 & + & - & + & + & - & + & - & - & 26,5 \\
\hline 6 & - & - & + & + & + & - & - & + & 17,6 \\
\hline 7 & + & + & + & + & + & + & + & + & 73,6 \\
\hline 8 & - & + & + & + & - & - & + & - & 53,2 \\
\hline
\end{tabular}

Висновки. Із результатів проведених дослідів можна стверджувати, що на процес миття деталі в ультразвуковій ванні найбільший вплив мають температура розчину і тривалість процесу миття. На рис. 4-6 залежності надзвичайно близькі до лінійних, за збільшення усіх параметрів збільшується відсоток змитого забруднення.

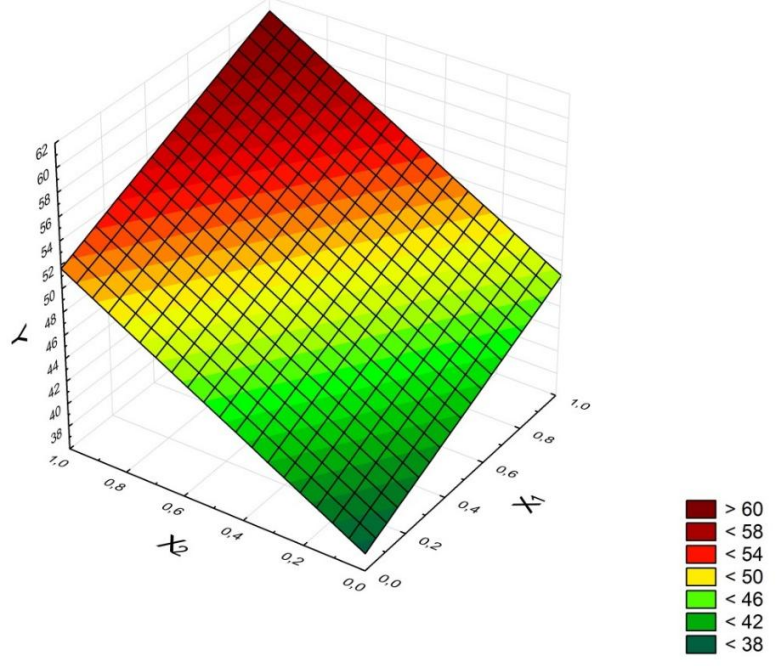

Рис. 4. Поверхні відгуку $Q=f(t, T)$

Fig. 4. The response surfaces $Q=f(t, T)$

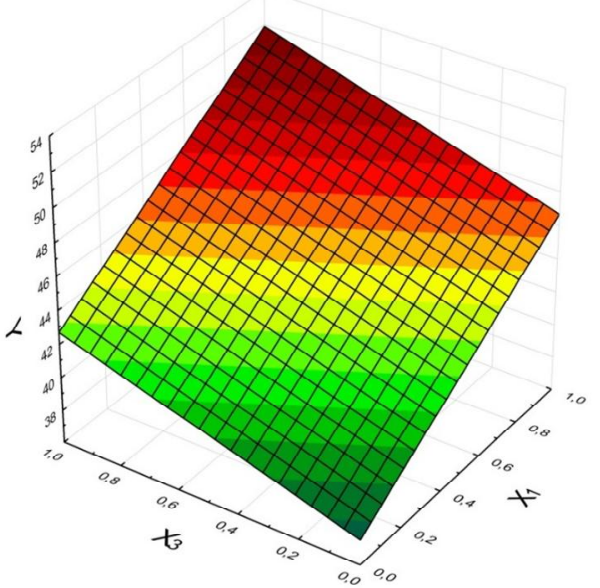

Рис. 5. Поверхні відгуку $Q=f(t, p)$

Fig. 5. The response surfaces $Q=f(t, p)$ 


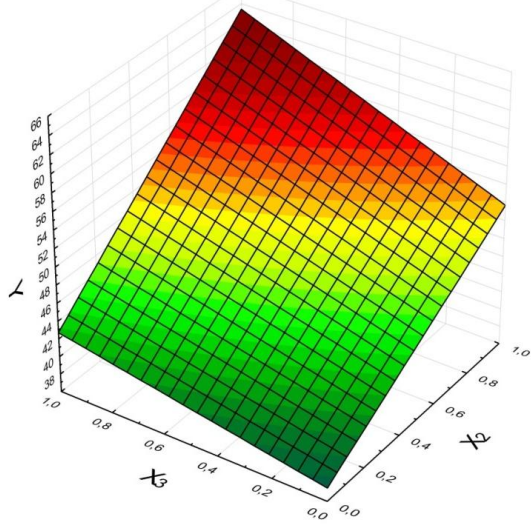

Рис. 6. Поверхні відгуку $Q=f(T, p)$

Fig. 6. The response surfaces $Q=f(T, p)$

Рівняння регресії (3) в розкодованому вигляді дає змогу визначити відсоток змитого забруднення при підстановці значень тривалості процесу миття, температури розчину i концентрації мийних речовин, що лежать в області експерименту

$$
5 x_{B} \leq t \geq 15 x_{B}, 40^{\circ} C \leq T \geq 80^{\circ} \mathrm{C}, 5^{2} / \pi \leq p \geq 25^{2} / \pi \text {. }
$$

Аналіз поверхонь відгуку дає підстави до проведення майбутніх досліджень для встановлення оптимальних значень концентрації мийних речовин, тобто досягнення оптимуму, при якому збільшення концентрації мийних речовин суттєво не впливає на очищення деталі.

\section{Бібліографічний список}

1. Адлер Ю. П. Введение в планирование эксперимента. Москва: Металлургия, 1969. С. 162.

2. Вайншток И. С. Ультразвук и его применение в машиностроении. Москва: МАШГИЗ, 1958. С. 69-74.
3. ГОСТ 11.006-75. Прикладная статистика. Правила проверки согласия опытного распределения с теоретическим. Москва: Изд-во стандартов, 1981. 32 с.

4. Келлер О. К., Кратыш Г. С., Лубяницкий Г. Д. Ультразвуковая очистка. Ленинград: Машиностроение, 1977. $183 \mathrm{c}$.

5. Моркун В. С., Кравченко О. М. Основні напрямки вдосконалення керування процесом ультразвукового очищення. Вісник Криворізького національного університету. 2019. Вип. 49. С. 3-9.

6. Панов А. П. Ультразвуковая очистка прецизионных деталей. Москва: МАШГИЗ, 1984. 88 с.

7. Чернишов О. В., Музичка Д. Г., Трикіло А. І., Яновський В. А. Підвищення ефективності процесу очищення металевої стружки від мастильно-охолоджуючих рідин за допомогою миючих розчинів. Вісник КрНУ імені Михайла Остроградського. 2018. Вип. 5 (112). С. 103-109.

8. Fuchs F. J. Ultrasonic Cleaning: Fundamental Theory and Application. URL: https://ntrs.nasa.gov/ citations/19950025362 (Last accessed: 01.06.2021).

9. Hicks Charles R., Kenneth Turner V. Fundamental Concepts on design of Experiments. Oxford University Press, 1999. 576 p.

10. Johnson N. L., Leone F. C. Statistics and Experimental Design in Engineering and the Physical Sciences. New York, 1977. Vol. 1. 595 p.

11. Mason T. J. Ultrasonic cleaning: an historical perspective. Ultrasonics Sonochemistry. 2016. 29. P. 519-523.

12. Verhaagen B., Rivas D. F. Measuring cavitation and its cleaning effect. Ultrasonics Sonochemistry. 2016. 29. P. 619-628.

13. Vetrimurugan, Lim T. Experimental Investigation of Ultrasonic and Megasonic Frequency on Cleaning of Various Disk Drive Components. International Journal of Chemical Engineering and Applications. 2013. Vol. 4, No. 4. P. 174-177.

14. Weller R. N., Brady J. M., Bernier W. E. Efficacy of ultrasonic cleaning. Journal of Endodontics. 1980. Vol. 6, issue 9. P. 740-743. 